\title{
Editorial
}

László Károly*

\section{Memores acti prudentes futuri}

https://doi.org/10.33063/diva-377851

Together with its predecessor Le Monde Oriental (1906-1946), Orientalia Suecana (1952-) represents a more than century-old tradition of scholarly publishing in the field of Oriental studies at Uppsala University. During the decades after its foundation, it became a recognized name among scholars and one of the leading organs of its kind.

Most of the contributions in the early volumes were primarily philological, i.e. studies of historical sources with a wider view towards historical, and especially religious-historical issues. More recently, though, alongside the articles dealing pre-modern issues, Orientalia Suecana has begun to publish numerous studies on contemporary topics and phenomena. In addition, "purely" linguistic and literary research have also found their place in Orientalia Suecana.

In 1952 Erik Gren, the founder of the journal, described its mission as follows: "research in Oriental studies in Sweden will be promoted by this enterprise. We also hope that the new journal will be a means of strengthening that international co-operation which is an indispensable condition for successful work in this field of study." This enterprise became, without doubt, a success story.

Times change, however, and coping with new challenges is not always a straightforward matter. The last twenty years have involved more changes and challenges than the entire preceding century. Conventional academic organs deeply rooted in print-based ecosystems have had to adapt to new conditions to continue disseminating their knowledge in accordance with today's needs, requirements, and expectations. For "early birds" this was a gradual process causing little or no trouble, but for "sleepy heads" it has been a rather painful venture. The Open Access movement, often considered to be an integral part of the new ecosystem, has also caused some disturbances in academic circles.

In 2012 the editorial board of Orientalia Suecana decided that further issues of the journal would only be published in electronic form. This was the right step at the right moment, one might think, but various external and internal problems caused an unfortunate period of stagnation in the life of the journal. Not a single research article was published between 2012 and 2018, a fact best not ignored, and one that had serious consequences for the journal's reputation and credibility.

Nonetheless, preserving and continuing the tradition laid down by the founder of Orientalia Suecana still appears to be a worthy undertaking. A number of professors at the Department of Linguistics and Philology, Uppsala University, have therefore decided to preserve and revitalize this old and internationally recognized journal. Almost "beyond the last hour of miserable man" a new editorial board has been formed that, for the first time in the history of the journal, includes external members from other Scandinavian countries - one of the new requirements defined by regulatory bodies and funding agencies. Another major change is the adaptation of the Diamond Open Access publishing model, which provides free access to peer-reviewed journal articles without charging article-processing fees. Moreover, the articles will be published individually without any further delay after final proofs are returned by authors. This allows for quicker publication of authors' research results.

There are, however, two cornerstones of the journal that the editorial board does not plan to change: its scope, as briefly described above, and its original mission, as stated by Erik Gren.

* Department of Linguistics and Philology, Uppsala University, E-mail: Laszlo.Karoly@lingfil.uu.se.

Open Access. Published by the Department of Linguistics and Philology, Uppsala University. This work is licensed under the Creative Commons Attribution-NonCommercial-NoDerivatives 4.0 International license. 
The editorial board:

Ildikó Bellér-Hann - Department of Cross-Cultural and Regional Studies, University of Copenhagen, Denmark Eleanor Coghill • Department of Linguistics and Philology, Uppsala University, Sweden Joakim Enwall • Department of Linguistics and Philology, Uppsala University, Sweden Carina Jahani • Department of Linguistics and Philology, Uppsala University, Sweden Juha Janhunen - Department of Languages, University of Helsinki, Finland László Károly • Department of Linguistics and Philology, Uppsala University, Sweden Heinz Werner Weßler • Department of Linguistics and Philology, Uppsala University, Sweden Claus Peter Zoller • Department of Culture Studies and Oriental Languages, University of Oslo, Norway 